provides some empirical support for the belief that junior doctors should be cared for not only for their own sakes but also for that of their patients. I hope that this kind of evidence will speed up the day when junior doctors are valued and supported as they should be.

DR TONY HOPE, Oxford Practice Skills Project, Medical School Offices, John Radcliffe Hospital, Oxford.

\section{Who am I? Identity, Adoption and Human Fertilisation}

Christine Walby and Barbara Symons, 127 pages, London, £9.95, British Agencies for Adoption and Fostering, 1990

The Human Fertilisation and Embryology Act 1990 was fully implemented by the end of last year. The contention of this book is that the code of practice governing the Statutory Licensing Authority, and the regulations made by the Secretary of State, should be informed by knowledge gained from the closest parallel in human relationships - the adoption of children by substitute parents, involving the severance of legal ties with members of the biological family.

This booklet charts the historical development of adoption in our society, including the change of emphasis from adoption being regarded as largely a solution to the problems of adults to an emphasis on the importance of decisions being based on the best interests of the child. It also describes the process, the rationale and the dilemmas which have resulted in the shift in adoption philosophy and practice from confidentiality and secrecy being paramount towards carefully controlled access to information and increasing openness. It is heartening that this development stems from research and feedback from participants in adoption, not from abstract principles and unfounded assumptions. The issues which emerge are all highly relevant to the current debate about the ethics of human fertilisation by donor, and surrogacy for commissioning parents.

The authors demonstrate that the conflict between a 'laissez faire' attitude, and agencies taking some responsibility for decisions regarding fitness for parenthood, is of crucial significance. Reliable findings highlight the importance of a recognition of the difference between biological and other forms of parenthood. The denial of reality has been found to have an unfavourable impact on relationships within the family. The authors furnish sound arguments for formal selection procedures, which explicitly acknowledge the responsibilities to children, and the adults they will become, inherent in direct social or medical intervention to create families, and which signify an official refusal to collude with pretence. It may be inimical to the medical profession to make judgements regarding eligibility for 'treatment', but there is ample evidence that preparation for parenthood, especially when it involves the extra dimension associated with adoption or human fertilisation, confers lasting benefits. Although this should be seen primarily as an educative process, rather than a series of hurdles, adults who were adopted as children are clear that an assessment procedure should attempt to ascertain the state of mental and physical health of prospective parents, as well as the quality of the marriage or partnership, if one exists. Damaged individuals, or couples, are unlikely to be able to cope with the extra vulnerability inherent in the highly complex set of relationships established by adoption or donor fertilisation.

The authors also discuss the implications of 'genealogical bewilderment', a condition described by thousands of adopted people worldwide, whose formation of a sense of identity has been hampered by lack of information about their heredity. The establishment of a clear, integrated understanding of one's identity is a prerequisite for the development of healthy emotional and social maturity. This secure concept of self, based on acceptance and trust, can only be built on a foundation of honesty and knowledge. Living a lie will take its toll on parents and child alike. This places an obligation on practitioners to furnish parents with adequate, written information about a child's biological background, and to attempt to ascertain willingness and ability to communicate to the child about his or her origins.

Research indicates, however, that a requirement to explain the truth is not the same as making this possible or sufficient. The amount and accuracy of information, and an atmosphere of open communication, whereby the meaning and implications of having two sets of parents are reiterated and explored at appropriate stages, are critical. Research in the field of adoption has revealed that parents cannot be adequately prepared for the inherently painful and on-going task of explaining in advance. Help, in the form of skilled and experienced counselling, should be available, as an entitlement, subsequently. This raises the crucial question of continuing services for families which have been created as a result of sperm or embryo donation.

This lively, informative and lucid book provides convincing arguments for making a close comparison between the field of adoption and people conceived through human fertilisation techniques. It would be unethical to ignore the lessons gained from adoption about the need to balance the rights and needs of all the parties involved in those delicate transactions which involve transferring children from one set of parents to another.

DIANA REICH Post Adoption Centre, 8 Torriano Mews, Torriano Avenue, London NW5 2RZ

\section{The Human Embryo: Aristotle and the Arabic and European Traditions}

Edited by G R Dunstan, 246 pages, Exeter, $\{25.00$, University of Exeter Press, 1990

The jacket-illustration of this book depicts St Hildegard's vision of the ensouling of the human embryo. This vision draws on a tradition going back at least to Aristotle, in which the action of the male semen on the female menstrual blood at conception is compared to that of rennet on milk in cheese-making. Delightfully quaint, one might think, but hardly relevant to the questions so urgently raised by the Human Fertilisation and Embryo Act.

This collection of essays is published in the hope that past science is more than a dead letter. It traces some crucial moments in the tradition of enquiry into human reproduction, culminating in an admirably clear article on the embryo in contemporary medical science by Braude and Johnson, which takes care to emphasise points relevant to current ethical and social-policy debates. Ideally the reader interested in ethics will benefit from the other specialist 
contributions on the historical background, in that the accounts will be more soundly-based and more nuanced than the casual gleanings from secondary works which are the rule in contemporary discussion. But more than antiquarian interest is required; a history of two-and-a-half thousand years of argument should contextualise current positions in the debate.

Most helpfully, these articles do deepen understanding of the complex evolution of religious attitudes to the embryo. They outline the history of the transmission of Greek speculation through Islamic science and theology to mediaeval Christendom and beyond. The crucial aspect of this process for ethics is that, from the beginning, understanding of the nature of the potential human being from prefertilisation to birth bore on its moral status. The metaphorical framework drawn from the agrarian culture of Greece led to an understanding of the embryo as plant-like in Hippocratic writings, as King shows. In Aristotle, though possessing soul potentially, it passes through stages, from the plantlike to the animal-like, when it acquires sensation. Already moral status is determined, since abortion should ideally be carried out before sensation 'and life' have begun. ThomistAristotelian doctrine, setting out a specific time-limit of animation, continues to inform Christian attitudes up to Pope Pius IX, who rejected the notion of ensoulment in 1869: 'life' was to begin at conception.

The complex details of the vicissitudes of the tradition found in these articles may prove daunting to the casual reader, especially where Latin remains untranslated, as in Brockliss's article on the embryological revolution in the France of Louis XIV, and it may be tempting to fall back on the more journalistic survey of fallacies in embryology through the ages by Seller, which sits rather oddly at the end of the collection. Dunstan's useful introduction and summary does however offer the chance to pick and choose in an informed manner.

Most of the authors content themselves with straightforward history of ideas rather than drawing out aspects of specific relevance for the modern debate. An exception is Goodman, who tacks on an anti-abortionist plea to an article on the Maimonidean view of the fetus as a natural miracle. Implications for the present are suggested more subtly by McLaren, who argues that it was neither new scientific observation, nor convincing philosophical argument which changed canon law and civil jurisprudence in the nineteenth century, but rather the desires of the Church on the one hand, and the doctors on the other, to control the decision and the means of terminating pregnancy, a decision hitherto left more to the women who were the only judges of when ensoulment had taken place. At the very least this article reminds us that the question: cui bono? and indeed its converse, should be borne in mind in listening to the participants in debates today.

TAMSYN S BARTON,

Research Fellow, Newnham College, Cambridge.

\section{Moral Knowledge}

Alan H Goldman, 224 pages, London and New York, £9.99, Routledge, 1990

Are some moral views true and others false? Do some people possess moral knowledge on certain matters while others languish in moral ignorance about them? These ancient questions have notoriously divided philosophers. Many, particularly in recent times, have been struck by the differences between empirical and moral questions and have supposed that, while talk of truth and falsehood, knowledge and ignorance, is appropriate in empirical enquiries, it is misplaced in moral ones. Other philosophers think that the distinction between facts and values has been exaggerated and that the notions of moral truth and knowledge are philosophically respectable and indispensable. The one side holds that grasping the fact-value distinction is the essential preliminary to an enlightened view of moral life, while the other fears that it is the preliminary to the extinction of that life, for without the notions of moral truth and knowledge is not any view as good as any other and therefore is not everything permitted?

This book by an American philosopher takes up these issues. It is one of a series entitled The Problems of Philosophy, Their Past and Present. Goldman distinguishes three broad positions on the issue in question. Moral realism holds that the world contains real moral properties independent of us, or at any rate of our beliefs about them, which render our moral judgements true or false. Goldman identifies differing versions of this view in the philosophies of Hobbes,
Hume and Kant, despite the rather more common conscription of the firs two into the ranks of anti-realism. Roughly half the book is devoted to an examination of this trio and Goldman is led to reject realism and their various versions of it. The second broad position that Goldman discusses, which he calls emotivism, holds that mora judgements express attitudes rather than refer to independent properties, and so lack truth-values. Rejecting this view too Goldman embraces coherentism, according to which a moral belief is true if it coheres best with other moral and non-moral beliefs Unlike emotivism this view preserves the notions of moral truth and knowledge, but rejects the realist account of moral truth in terms of correspondence with moral properties. Goldman compares morality with law, for what makes a legal decision correct is not correspondence with some mysterious legal reality, but rather coherence with the existing body of legal propositions. Moral truth turns out to be more like truth in law, than like empirical truth.

The comparison with law is an illuminating one, but the moral case remains more complex. Moral issue display a great variety which may itse contribute to the persistence of the debate between realism and emotivism If one is considering whether or not it is right to keep promises, then moral realism looks very plausible in view of certain evident facts about the human situation which seem to make the keeping of promises an unavoidable requirement of any morality. By contrast emotivism becomes more appealing in the case of sophisticated dilemmas such as that of Sartre's young man in L'Existentialisme est un Humanisme, where the insistence that there is a moral truth about what to do seems very implausible. (Sartre picked his example shrewdly.) One way to advance the debate between realists and emotivists might be to enhance our sense of the variety of moral issues.

This is a solid but unseductive book. Uninvitingly difficult for the novice, the book may leave initiates with a sense of professional competence, but heaviness, unrelieved by any imaginativeness about the wider implications of this fundamental issue.

WILL CARTWRIGHT, Department of Philosophy, University of Essex. 